\title{
MEDEAS EN LA FRONTERA: LA TRADICIÓN CLÁSICA EN TRES PIEZAS TEATRALES LATINOAMERICANAS
}

\author{
Francisco Bravo de Laguna Romero \\ Instituto Universitario de Análisis y Aplicaciones Textuales \\ Universidad de Las Palmas de Gran Canaria
}

\section{Resumen}

El mito de Medea está presente en numerosas adaptaciones teatrales iberoamericanas y su trascendencia ha sido suficientemente analizada en importantes estudios y monografías. El objeto de este trabajo es revisar tres obras dramáticas latinoamericanas escritas en la década de los años cincuenta, La Selva del peruano Juan Ríos, Além do rio del brasileño Agostinho Olavo y La Frontera del argentino David Cureses, que comparten el mito de Jasón y Medea como elemento estructural, y que sitúan su acción dramática en límites fronterizos en el tiempo idealizado de la conquista de América.

Palabras clave: Tradición clásica, teatro latinoamericano, Medea.

\section{MEDEAS IN THE FRONTIER: CLASSICAL TRADITION IN THREE LATIN AMERICAN THEATRE PLAYS}

\begin{abstract}
The myth of Medea is present in many Ibero-American theatrical adaptations and its relevance has been widely studied in both extensive works and monographs. The aim of this paper is reviewing three Latin American theater plays written in the 1950s, namely, La Selva (The Jungle) by the Peruvian Juan Ríos, Além do rio (Beyond the river) by the Brazilian Agostinho Olavo, and La Frontera (The Frontier) by the Argentinian David Cureses. The three works incorporate the myth of Jason and Medea as a structural element and they locate the main plot in the borderline of the idealized period of the Conquest of America.

Keywords: Classical tradition, Latin American theatre, Medea.
\end{abstract}




\section{INTRODUCCIÓN}

La producción teatral sobre la Conquista tuvo una presencia casi continua en México a lo largo del siglo xx (Dolle, 2014: 27), pero esta producción no fue tan profusa en el resto de Latinoamérica, excepto en la década de los cincuenta, cuando se produce un auge de esta temática en relación con la discusión sobre la identidad y la historia colonial. En muchas de estas piezas los personajes femeninos tenían como referente más cercano a la figura de la Malinche, aunque siguiendo también el modelo clásico de Medea. No pretendemos hacer una revisión de todas estas Medeas, estudiadas en numerosos trabajos ${ }^{1}$, ni hablar del papel del mito clásico en el teatro contemporáneo latinoamericano ${ }^{2}$, inicialmente marginal, como apuntaba Miranda Cancela (2006), pero sobre el que se ha ido construyendo una sólida y profusa bibliografía ${ }^{3}$. El objeto de este trabajo es revisar tres obras dramáticas latinoamericanas escritas en la década de los años cincuenta que, con el mito de Jasón y Medea como elemento estructural ${ }^{4}$, sitúan su acción dramática en un periodo histórico, «mitologizado» e idealizado: la época de la conquista de América, un tiempo de enfrentamientos étnicos y culturales. En el contexto de debates político-sociales, históricos e identitarios de los años cincuenta, surgen tres obras ${ }^{5}$ que se mueven en un paisaje mágico, transitado por dos tiempos míticos: La Selva del peruano Juan Ríos $(1950)^{6}$, a comienzos del siglo Xvi, en la selva amazónica, en el inicio de la conquista de América; Além do rio del brasileño Agostinho Olavo (1957)7, en el

1 Entre otros, Clauss y Johnston (1997), Gentili y Perusino (2000) y Pociña y López (2002 y 2007).

2 Cf. Hualde Pascual (2012).

3 Entre otros, Bosher et al. (2015). Al estudio de estas adaptaciones y revisiones, también nos hemos acercado puntualmente (Bravo de Laguna, 1999; 2003; 2010 y 2015).

4 Tomamos los modelos de Eurípides y Séneca como referencias básicas pero, aunque no los citemos, no desdeñamos los antecedentes griegos de Píndaro (Pítica IV), y Apolodoro, ni los latinos de Ovidio con sus Heroidas. Para una revisión más exhaustiva y profunda sobre las referencias y la influencia de los temas y motivos del mito de Jasón y Medea, cf. Harrauer y Hunger (2008: 523-530).

5 No incluimos en este trabajo Malinztin, Medea americana, del mejicano Jesús Inclán (1957), un drama en tres actos, en verso y prosa, alejado de los parámetros iniciales de este estudio.

6 En 1950 ganó el Premio Nacional de Teatro y fue estrenada en 1951. Está dividida en tres actos y desarrolla el mito de Medea entre indígenas y conquistadores. El personaje de «El Soñador» es el hilo conductor que sostiene poéticamente el relato mítico de La Princesa, Medea, y El Capitán, Jasón. Evoca cada uno de los episodios desarrollados en el mito griego: el descuartizamiento de Absirto (sic), la muerte de Pelias a manos de sus hijas, instruidas por Medea; la petición de exilio de El Gobernador, Creonte; la muerte de su hija, prometida de El Capitán, el asesinato de los niños y la inmolación de Medea.

7 Fue publicada en 1961, en una antología de Abdias do Nascimento, fundador de $O$ Teatro Experimental do Negro (Nogueira Coelho, 2015: 160). La trama se sustenta en tres bases: la tragedia 
Brasil colonial y esclavista, del último cuarto del siglo xvir; y La Frontera del argentino David Cureses $(1960)^{8}$, a finales del siglo xix, en la época de la Conquista del Desierto ${ }^{9}$ al sur de la Argentina.

\section{LA FRONTERA EN CLAVE INTERPRETATIVA, COMO SÍMbOLO Y METÁFORA}

Estas obras, por lo tanto, comparten dos características fundamentales que las conectan como contexto creativo: la década de los cincuenta y el espacio-tiempo dramático. Tienen, además, un componente estructural común que termina de vincularlas de manera absoluta. En todas ellas, la frontera, el límite, actúa como paisaje y personaje, como borde indefinido que se convierte en símbolo real de la esencia cultural de Latinoamérica. En estos márgenes inciertos, que determinan la certeza de la abstracción intercultural del continente, se mueven estas tres obras.

El corpus de literatura de frontera en América Latina es extenso y en numerosas ocasiones está vinculado a la conquista del territorio y a la lucha contra el indio (Servelli, 2010: 31). No pretendemos identificar las características de la literatura de frontera presentes en estas obras ni definirlas ${ }^{10}$, pero sí es cierto que la frontera entendida como tierra virgen y tierra de nadie

griega, las cantigas folclóricas y los cantos de los ritos africanos (Martins, 1991: 131). Medea es una reina africana, Jinga, que traiciona a su pueblo por el amor de Jasón, un comerciante de esclavos. Antes de dejar su patria, Costa de Marfil, mata a su propio padre y envenena a su hermano. A los pocos años, al conocer el futuro matrimonio de Jasón con Creúsa, la hija de Creonte, la mata con un hechizo mortal y asesina a sus hijos para que su padre no se los lleve.

8 Fue estrenada en el Teatro El Gorro Escarlata el 2 de diciembre de 1964 y galardonada con el Premio Argentores 1960 al mejor drama. Compartimos plenamente la opinión de Pociña (2007), quien asegura que Cureses se pudo inspirar en la obra de Leopoldo Marechal, Antígona Vélez, estrenada nueve años antes. La india Bárbara mata a su padre, el Cacique Coliqueo, y a su hermano, y se levanta contra su pueblo para proteger a su amante el Capitán Jasón Ahumada que quedó abandonado por su tropa, herido y solo en el desierto. Bárbara es, al mismo tiempo, la madre adoptiva de dos huérfanos, Huinca y Botijo, a los que, siendo niños, los salvó de la muerte y los crió, y la madre biológica de dos hijos concebidos del Capitán Jasón Ahumada. La acción se desencadena cuando el Coronel Ordóñez, Creonte mítico, llega con la intención de llevarse a sus hijos, Botijo (personaje que tiene muchas conexiones con el niño raptado del relato de Borges «El cautivo») y Huinca (término procedente del mapuche que significa «Nuevo Inca» y se aplicaba a los blancos, conquistadores españoles del desierto pampeano a partir del siglo Xvi; el personaje de «La Vieja» así nos lo recuerda: «A vos te apelamos Huinca... por ser crestiana», pág. 9). También advierte a Bárbara que debe abandonar el rancho porque su hija Huinca, Aurora cristiana a partir de este momento, se ha enamorado de Jasón. Bárbara enloquece y, por mediación del indio Anambá, asesina a Aurora-Huinca y envenena a sus hijos.

9 «Desierto es el vocablo excluyente utilizado a lo largo del siglo xIx para referirse al territorio sometido a la influencia del indio», y es complementario al uso de la palabra «frontera» (Servelli, 2010: 33).

10 Como ejemplo de este tipo de estudio, Biglieri (2015). 
se presenta como espacio ideal para su incorporación a la cultura occidental y no hay mito tan productivo como el de Medea para realizar tal labor.

\subsection{Frontera étnica}

Esta frontera interior, la racial, es la primera y la más visible de todas las fronteras, especialmente en América Latina. Esta separación se convierte en límite social, cultural y emocional, entre un mundo indígena y criollo, entre negros y blancos, entre identidades separadas por realidades históricas. Esta línea divisoria solo esconde una asociación perversa entre lo civilizado y lo bárbaro, representado por indios despreciados, herejes y pordioseros, adoradores de la magia, y Medeas guerreras y salvajes:

Hijo 1.: ¡Mi madre es princesa!

Hijo 2..: (Con desprecio) ¡Pero india! (Ríos, 1961: 413).

Bárbara: Tuitos éramos indios, herejes, pordioseros de la pampa, maestros de brujería (Cureses, 1964: 36).

Este antagonismo separa, igualmente, el mundo negro y el blanco, especialmente en Além do rio. En un mundo de blancos, de juego de blancos, incomprensibles y enigmáticos, de sentimientos de blancos, no hay lugar para los negros:

III LAvadeIra: Negra suja! Feiticeira! (Olavo, 1961: 201).

MedeA: Além do rio ficam os brancos. Não lugar para mim (Olavo, 1961: 217).

NoDriza: ¡En el alma de los blancos hay regiones impenetrables para nosotros! (Ríos, 1961: 446).

La Princesa: No os asustéis. Es un juego, un juego de blancos (Ríos, 1961: 517).

\subsection{Frontera religiosa}

Este límite tiene una doble lectura. Por un lado, la única posibilidad de pertenecer al mundo civilizado es la conversión al cristianismo. Este es el caso de Medea en Além do rio. Su integración y aceptación social solo se produce por la negación de sus prácticas religiosas y su conversión al cristianismo. Durante toda la obra recuerda siempre que fue bautizada y que está prometida a Jasón, y, por consiguiente, está a las puertas de materializar otro sacramento más. Y eso la convierte en miembro de pleno derecho de la comunidad $^{11}$ : «Os brancos me batizaram Medea e eu prometi a Jasão»; «Fui batizada e prometi a Jasão (Olavo, 1961: 204 y 209).

11 No olvidemos que tanto en Atenas como en Roma el extranjero no tenía derecho al culto, ni siquiera tenía derecho a invocar a los dioses de la ciudad. 
Sin embargo, desde la otra orilla la lectura es diferente: los valores del mundo cristiano se envilecen y las virtudes cristianas se convierten en defectos ante los ojos de los indígenas, lo que permite componer un retrato de avaricia, odios y venganzas, propio de una civilización enferma y caduca. No saben amar, odian y mienten como cristianos y adoran a un dios miserable y mezquino:

LA NoDriza: Los cristianos no saben amar profundamente (Ríos, 1961: 446).

La Princesa: El oro es el único dios en que confían los cristianos (Ríos, 1961: 459).

Bárbara: El Dios de ustedes nada nos dio, dende que por primera vez oímos hablar de Él, tuito jué pa mal (Cureses, 1964: 18).

BÁrbara: Es tu padre... Viene a buscarte pa que seias un crestiano de verdá... como él... pa que sepas mentir... y odiar... (Cureses, 1964: 33).

\subsection{Frontera geográfica}

Esta frontera, más política, social y cultural, que geográfica, representa la oposición Norte-Sur, el conflicto entre países y economías enriquecidas frente a regiones empobrecidas. En el Norte, donde habitan los blancos, cristianos y ricos, está la civilización, se organizan las leyes y las haciendas venden y compran esclavos; el Sur, primitivo y salvaje, representa un paisaje idealizado, un lugar natural alejado de los ruidos desordenados de una civilización voraz:

C. OrdóñEz: Hacia el Norte, estamos nosotros, la civilización que avanza (Cureses, 1964: 18).

C. ORDóñEz: Varias leguas más al sur, donde la pampa se torna como el filo de un cuchillo por lo salvaje (Cureses, 1964: 18-19).

Ama: Mas os negros não se esquecem nas plantaçoes do Norte, onde ficaram vendidos (Olavo, 1961: 206).

La Nodriza: Nuestro pueblo no es salvaje. Lejos, muy lejos, allá en el sur, bajo el dorado sol que lo ilumina ha construido templos y ciudades en selvas y montañas (Ríos, 1961: 389).

En definitiva, todo termina reduciéndose a una oposición entre «los de aquí y los de allá» ${ }^{12}$; los de un lado y los de otro, con un límite tan ancho e indefinido como invisible e infranqueable. Así, en La Frontera:

12 Imagen que parece tomada del ensayo sobre Martín Fierro de Martínez Estrada (1983: 485-486): «A un lado, lejos, están los indios; al otro, lejos, los que gobiernan, legislan y juzgan... Son seres fronterizos, especie de mestizaje de dos formas de vida más que de dos razas». 
Huinca: ¡Tuitos iguales!... Sí... pero ellos siguen siendo loj de allá y nosotros loj de acá... El límite está en el medio... nadie lo ve pero está... ancho, grande, tanto que no se puede cruzar... y nosotros, Botijo... vos y io... somos del otro lao... aunque estemos d'este... D'este están la Bárbara... y la Vieja (Cureses, 1964: 15).

BÁrbara: Io estoy aquí y ellos allá y la frontera está en medio (Cureses, 1964: 25).

\subsection{Frontera natural}

Lo que en la tradición clásica estaba compuesto por dos espacios geográficos, Cólquide y Corinto, que representaban dos culturas, lo no-griego frente a lo griego, en estos dramas latinoamericanos el antagonismo comparte territorio (Fernández Bravo, 1999) y el paradigma Nomos frente a Phisis (Delbueno, 2013) separa estos dos mundos.

Esta línea divisoria se convierte en el espacio mítico y dramático donde se desarrolla la acción. Y estas fronteras están trazadas por límites naturales como el río, la selva o el desierto, que mantienen a Medea alejada de su esencia y de su condición. Este límite natural está diseñado con la misma función estética, simbólica y dramática en las tres obras. De este modo, aunque diferentes, son los mismos escenarios: una isla habitada, separada de la civilización por un río ${ }^{13}$; el rancho en la frontera, «una isla en mitad de la pampa», una fortaleza en medio del «desierto»; o la selva, onírica, salvaje y terrible.

Uma ilha formada no cotovêlo de um rio (Olavo, 1961: 200).

La escena se desarrolla en una playa del continente americano. La selva se levanta rumososa, siniestra, al fondo y a la izquierda (Ríos, 1961: 393).

Todo alrededor es campo, campo abierto y desierto... Isla en mitad de la pampa, del fortín y de la posta... (Cureses, 1964: 7).

En definitiva, río, selva o desierto, todos son fronteras, límites donde Medea rompe con sus raíces o se protege de sus enemigos. Todos representan el primitivo origen de su raza, su cultura, su religión, su tradición, y a ellos la protagonista termina regresando al final de cada una de las piezas, cerrando, de este modo, el discurso metafórico.

13 El río simboliza el elemento natural que separa las naturalezas culturales de los protagonistas, allá del otro lado del río, além do rio: «VIEJA: Ayer, los caranchos formaron una corona, allá del otro lado del río... en donde antes estaban las tolderías» (Cureses, 1964: 10); pero también representa la personificación maligna de una voraz corriente que fluye demoníaca pidiendo sangre: «EL SoÑADOR: También el río quiere sangre!» (Ríos, 1961: 407); «EsPAÑOL 2. : ¡Oye al río borracho carcajeándose a mandíbula batiente!» (Ríos, 1961: 409). 
En La Selva, la simbología anuncia el homenaje al linaje y a la estirpe a la que pertenece Medea: el Sol. La Princesa, tras asesinar a sus hijos y beber un vaso de veneno, avanza hacia la casa en llamas que ella misma ha prendido. Se libera y purifica, como la Medea clásica, con el sol y el fuego: « $\mathrm{Ah}$, incendio, sol de los desastres, dios de los vencidos: te saludo!» (Ríos, 1961: 524).

En Além do rio es el río el que acoge a Jinga-Medea, pero no el río sagrado que ya recibió los cadáveres de sus hijos, sino el palenque, la Villa João, donde los negros de su raza la reciben ya transformada de nuevo en reina, en Jinga:

MedeA: A negra largou o branco. Medea cospe êste nome e Jinga volta a sua raça, para de novo reinar... (Uma macumba sangrenta festejam a volta de Medea a raça) (Olavo, 1961: 231).

En La Frontera Bárbara abandona la escena camino a la soledad del desierto acompañada por los caranchos, carroñeros alados que simbolizan a las Furias o Erinias clásicas. No podría haber elegido Cureses una mejor simbología para finalizar su obra y conectarla, de este modo, con la tradición y el referente del que se nutre. El desierto es el destino final de esta Medea pampeana:

VIEJA: ¿Ande iremos?

Bárbara: Al desierto... Más allá de tuitas las fronteras... Sola... jal desierto! Sola... sola... sola... sola... (Cureses, 1964: 72).

\subsection{Frontera lingüistica}

La delimitación de las fronteras lingüísticas como elemento diferenciador de estos dos espacios geográficos, como un paso más allá de las oposiciones físicas, se articula en procesos diferentes en cada una de las obras.

En La Frontera la técnica es similar a la usada por José Hernández en Martín Fierro: la transcripción fonética de la lengua de los otros como demostración de diversidad lingüística ${ }^{14}$. Incluimos solo algunos ejemplos para no abundar en la repetición excesiva: «Io mesma; Quién t’iba a decir... si juías como ante luz mala; tuita cristiana»; «tuvimos que dir legüitas adentro; espérate qu'encuantito termine de derretir esto, entuavía de lo cuento otra vez»; «sos pior que las moscas e molesta»... (Cureses, 1964: 8, 8 y 10).

14 A este acertado juego, sonoro y efectista, de transcripciones fonéticas solo podemos hacerle una pequeña observación: el autor no respeta del todo sus propias reglas, es decir, no transcribe siempre igual. Quizás sea parte del recurso de reflejar la oralidad de los pueblos primitivos, pero también pueda deberse a erratas no intencionadas. 
Esta propuesta adquiere una mayor fuerza y relevancia en el segundo acto, donde se produce un cambio de registro. Los indios empiezan a hablar un castellano correcto porque el autor quiere producir en el lector la sensación de que los tres personajes indios hablan en su lengua natural ${ }^{15}$.

En La Selva Ríos propone el remedo devaluado de las voces de los indios como respuesta a las voces de los españoles. Los indios, a modo de Coro Bárbaro, siempre balbucean, desde la distancia, ininteligibles, violentos y amenazantes gritos, siempre al mismo compás, con la misma melodía: «Ala lala! ¡Ala lala! ¡Ala lala! ¡Ala lala!» (Ríos, 1961: 401, 414 y 440).

Como tercer recurso de frontera lingüística, estos autores comparten una técnica dramática que tiene mucha fuerza y presencia en una representación escénica: el sonido de tambores. No es casual que este lenguaje primitivo, reconocible y universal, sea un recurso que utilicen los tres dramaturgos, casi con las mismas implicaciones estéticas y metafóricas, exceptuando algunas matizaciones. Así, en Além do rio Medea promete a su amante abandonar los rituales africanos, pero se lo impide el sonido de los tambores que ejerce sobre ella una poderosa atracción:

III Lavadeira: Não ouve os tambores? Estão chamando Medea. [...]

II LAVAdEIRA: Mas chamando para quê? [...]

III Lavadeira: Digo que é mãe de santo e os espíritos só baixam, quando é ela quem canta [...]

Medea: [...] Mas por que me chamam assim? Por que não param de tocar? Ама: É o tantã de nossa gente. É a nossa raça chamando a sua rainha Jinga. Medea: Não me chame assim (Olavo, 1961: 203-204).

Los tambores de la escena final, que llaman a Medea, que le piden que regrese a su raza, es una constante sobre la que gira la pieza en todo momento. Los tambores varían sus ritmos, volumen e intensidad, pero siempre están presentes. Hasta cuando los tambores se silencian en la escena final, su presencia continua rondando, en la llamada angustiada de Medea, que clama para que vuelvan a tocar y le muestren el camino de regreso a su pueblo (Da Silva Carbalho, 2015: 23):

Medea: Vozes, ó vozes, da raça, ó minhas vozes, onde estão? Não ouso cruzar o rio e tenho medo da ilha, de seu silêncio tão grande. Ó vozes da minha raça, ó minhas vozes, onde estão? Por que se calam agora? A negra

15 Así lo explica Cureses (1964: 46) en la acotación que prologa el segundo acto: «La escena será jugada en un lenguaje distinto al resto de la pieza y los personajes que en ella intervienen usarán un tono también distinto. Es como si en verdad estos tres personajes indios, Bárbara, la Vieja y Anambá, hablaran en su idioma madre. Olvidados de la jerga que el continuo contacto con cristianos les obliga a hablar». 
largou o branco. Medea cospe este nome e Jinga volta a sua raça, para de novo reinar (Olavo, 1961: 231).

El regreso de Jinga representa su reintegración en su pueblo, reafirma su poder humano como reina y al mismo tiempo su poder sobrenatural como orisha. Eurípides rescata a Medea en un carro alado que vuela hacia el Sol; Olavo retorna a su Medea a su espacio original, «Costa do Ouro» representado en el quilombo, donde recuperará su identidad como negra:

Lentamente começam os atabaques, os tantãs e os agogôs a tocar um ponto de macumba. A floresta vai se iluminando de archotes. Vultos se recortam entre as árvores. São os negros fugidos, seminus, que numa macumba sangrenta festejam a volta de Medea a raça (Olavo, 1961: 231).

En La Selva los tambores también resuenan a lo largo de toda la obra y se deslizan sutilmente en las acotaciones ${ }^{16}$, evocando la presencia, siempre peligrosa, de la resistencia indígena. En esta obra, no obstante, estas acotaciones parecen más un recurso escenográfico que dramático:

Llega — desde el fondo y la izquierda - un lejano, monótono, sonido de tantán. Se oirá durante toda la escena (Ríos, 1961: 393).

El ruido del tantán aumenta poco a poco hasta volverse ensordecedor. Luego, cesa paulatinamente. Se ilumina la pieza (Ríos, 1961: 399).

Un alucinante estruendo de gritos y tambores cubre la voz del «Soñador» (Ríos, 1961: 401).

Mientras comienza a elevarse el sonido del tantán [...] Se obscurece completamente el escenario. Aumenta el ruido de los tambores. Luego, disminuye paulatinamente [...] El sonido del tantán es ahora casi imperceptible. Pero irá aumentando en intensidad hasta el fin de la escena (Ríos, 1961: 414-415).

Se obscurece el escenario. El ruido del tantán adquiere ensordecedora intensidad; luego, cesa bruscamente (Ríos, 1961: 426).

Se oye el ruido de lejanos tambores (Ríos, 1961: 430).

El sonido del tantán sigue «in crescendo» hasta el final de la lucha (Ríos, 1961: 440).

16 Cureses utiliza este mismo recurso del sonido de la melodía de fondo de los tambores, pero convertidos en "parches» que resuenan en el fortín: «Lejos como un trueno lejano se oyen batir los parches del fortín sonando»; «Durante el siguiente monólogo, el sonido de los parches lejanos se seguirá oyendo, como subrayando lo narrado por la vieja»; «Hay un silencio; solo se oye el sonido de los parches en el fortín»; «Los parches siguen sonando y su sonido se mezcla con la canción que a boca cerrada entonará Huinca dentro del rancho más fuerte»; «Se oyen los parches sonar más fuerte»; «BÁrbara: (Lejana)... ¿̇ís los parches, vieja?... Parece que me golpiaran adentro, en el corazón... en el vientre... No sé... no sé, pero siento como si me jueran a robar la vida»; «Lejos se siguen oyendo los parches» (Cureses, 1964: 7, 8, 9, 10, 11, 10 y 14). 
En esta ocasión no generan un efecto de llamada sobre Medea, sino el vaticinio de la presencia indígena sobre los conquistadores españoles. Los tambores no llaman a la tierra, no son liberadores, sino que presagian miedo y muerte, y se muestran amenazantes como las flechas y los gritos de los indígenas:

El Capitán: Los tambores.

ESPAÑol 3. : ¡Los indios! ¿Nos habrán visto?

El Capitán: Tal vez no. El ruido viene de lejos, de muy lejos...

EsPañol 2. ${ }^{\circ}$ : ¡Estás en el Infierno! ¡En un infierno de llamas verdes, con un millón de millones de demonios tañendo sus tambores! (Ríos, 1961: 394).

EsPaÑol $4 .^{\circ}:$ ¡LOS indios! ¡Los indios! ¡Los indios!...

ESPAÑOL $3 .^{\circ}:$ ¡Flechas!

EsPañol 5. ${ }^{\circ}:$ ¡Y gritos!

ESPAÑOL 3.': ¡Y tambores! (Ríos, 1961: 402).

EsPañol $4 .^{\circ}$ : ¡Una verdadera pesadilla, un sueño de la fiebre! ¡Corríamos como un eco delante de sus tambores! (Ríos, 1961: 417).

ESPAÑOL $1 .^{\circ}:$ ¡LOS tambores

EsPañol 3. : ¡Suenan cerca! ¡Cada vez más cerca! ¡Los siento palpitar como un tumor en medio de la nuca! (Ríos, 1961: 422).

\section{Frontera y mestizaje}

El mestizaje, como elemento integrador y como metáfora de fronteras, está muy presente en las tres obras. La dualidad representada en todas las fronteras, antes reseñada, y en los espacios físicos, culturales o sociales, que separan lo diferente, comparte una voluntad, y también una necesidad, de asumir este mestizaje como solución irremediable, formulación del deseo que encontramos en boca del personaje de Jasón en La Frontera: «Tu sangre india y mi sangre cristiana... un torrente que es necesario encauzar» $(\mathrm{Cu}-$ reses, 1964: 44).

Y para personificar este hecho diverso del mestizaje, no hay mejor simbología que los hijos de la indígena o la negra Medea y el criollo Jasón. Aunque su finalidad dramática y simbólica sea diferente en cada una de ellas, en las tres representan la identidad de un mestizaje desigual que se resuelve de manera diferente.

En Além do rio, como propone Da Silva Carbalho (2013: 18), los hijos de Medea, blancos y rubios, son la oportunidad perfecta de metamorfosearse en blanca, de convertirse en uno de ellos; son el argumento perfecto de su negación: dos puntas afiladas para cortar las cuerdas que la atan a su raza; dos criaturas, casi blancas, que convierten a Medea en una mujer casi blanca también: 
Medea: Meus filhos, de seus cabelos de ouro (Olavo, 1961: 207).

Medea: Sâo dois punhais afiados para cortar as cordas que me prenden a minha raça, dois leôzinhos dourados e me ligaram a outra gente (Olavo, 1961: 208).

Medea: Êles que me tornam quase branca (Olavo, 1961: 219).

São duas crianças, quase brancas. De cabelos alourados (Olavo, 1961: 223).

Para Martins (1991: 138), la muerte de sus dos hijos libera, como un fármaco, a Medea de su condición de madre y, del mismo modo, castiga a Medea y purifica a Jinga.

En La Selva cada uno de los hijos presenta visiones opuestas de la perspectiva del mestizaje: uno se inclina por el linaje materno (el Hijo 1. ${ }^{\circ}$ ama a su madre), el otro por el paterno (el Hijo $2{ }^{\circ}$ se avergüenza de ella ${ }^{17}$. Esta oposición quizás esconda un planteamiento más profundo y simbólico que pretende explicar el conflicto étnico de América Latina. La problemática racial, la negación de las identidades, se desliza en las palabras de los hijos de Medea: «Ambos son mestizos, pero los rasgos indios parecen más acentuados en el mayor», «¡Nosotros somos mestizos! ¡Mitad blancos, mitad indios!»o «iSoy blanco como ella, y no indio como vosotros!» (Ríos, 1961: 386, 413 y 512).

En La Frontera Cureses realiza la misma propuesta de la doble perspectiva étnica que desarrolla Ríos. Huinca rechaza su condición indígena y se enfrenta a Bárbara; Botijo, por el contrario, no acepta marcharse con su padre biológico, el Capitán Creonte, y reniega de su linaje cristiano. La novedad de Cureses, con respecto a los clásicos y a sus contemporáneos, es que Huinca, la hija adoptiva de Bárbara, se transforma en la Glauce mítica y se convierte en rival de Medea. Ambas son ahora una y eso redimensiona el efecto dramático de la tragedia. Aurora-Creúsa, antes indígena Huinca, quiere ser y estar en el otro lado de la frontera porque no siente que pertenezca a la pampa. Su amor por Jasón provoca no solo el odio incontenible de Bárbara sino el rechazo de su hermano:

Boтıjo: Ridordá también qu'el Jasón es tuito pa ella... Pienso en esa mujer que nos crió como si juéramos suyos... Io, al menos, no conozco otra madre (Cureses, 1964: 14).

Bárbara: ¿Pero qué sos vos?... ¿Víbora, alimaña?... hija e mala madre con tanto veneno dentro... que clavás el diente en la teta que te dio de mamar (Cureses, 1964: 30).

Este giro argumental magnifica, y casi justifica, la violenta reacción de Bárbara, porque es casi su sangre la que la traiciona, como ella traicionó a

17 Ríos (1961: 413): «Hıjo 1.: ¡Tú odias a la madre! ¡Tú la odias! / Hijo 2..: ¡Me avergüenzo de ella! ¡No la odio!». 
su padre y a su pueblo. Sus hijos biológicos, «sus cachorros», se mantienen siempre, al modo clásico, ausentes y fuera de escena.

\section{Otros habitantes de la frontera}

Título, motivos, coro, unidades de lugar y de tiempo, son los ingredientes en los que obligatoriamente, como apuntaba Lasso de la Vega (1981: 223), coincide cualquier Medea moderna. Como no podía ser de otra manera, los tres autores se mantienen fieles a los cánones establecidos y perpetúan la redimensión trágica del conflicto, cercana a Eurípides y Séneca. Sin embargo, en la estructuración de los diferentes coros y en la caracterización de los personajes, estas obras muestran ciertas distancias con respecto al original. «Contaminados» por el uso de contextos populares propios de las culturas indígenas, como la religión afrocubana, la música o la presencia de una tipología social característica, sus perfiles se matizan simbólicamente. A continuación analizaremos la vinculación con la tradición clásica de una serie de elementos estructurales y de estereotipos trágicos.

\subsection{El coro y los equilibrios raciales}

El coro y el equilibrio racial de los personajes en las tres obras mantienen una composición equitativa de elementos indígenas, o negros, y criollos o blancos.

En La Selva, como bien reza en las anotaciones iniciales, «la Nodriza, la Princesa, los Guerreros y el Príncipe visten a la manera india; los demás personajes, a la usanza española del siglo XVI» (Ríos, 1961: 382).

En Além do rio destaca el equilibrio, casi paralelo, de personajes negros y blancos: cuatro negros (Medea-Jinga; Ama; Batista y Serafim) y cuatro blancos (Egeu; Creonte; Creúsa y Jasón).

En La Frontera los blancos están encarnados por personajes masculinos que representan una autoridad, militar o eclesiástica: el Capitán Jasón Ahumada, el Coronel Ordóñez, y los dos frailes, Fray Javier y Fray Gaudencio, que actúan como mensajeros clásicos; el mundo indígena, por otra parte, está representado por personajes femeninos primitivos: la india Bárbara y su nodriza.

Los coros mantienen también un mismo equilibrio en la composición racial de sus miembros. En La Selva, las Voces de los Niños, las Voces de los Españoles y las Voces del Pueblo, simbolizan el mundo criollo y siempre se alzan, como una sola voz, ejecutando la sentencia de una comunidad que aborrece, maldice y condena la presencia indígena representada por La Princesa y sus hijos: 
Voces de los Niños: ¡Nieto del salvaje! ¡Hijo de la bruja! ¡Hijo del vagabundo!... ¡Hijos de la bruja! ¡Hijos de la bruja! (Ríos, 1961: 386-387).

Voces del Pueblo: ¡Muerte a la hechicera y a sus hijos! ¡Muerte a la hechicera y a sus hijos! ¡Muerte a la hechicera y a sus hijos! (Ríos, 1961: 517, 521 y 523).

En Além do rio la oposición se produce entre el Coro de Blancas (Lavanderas I, II, III) y los tres coros de negros (Vendedores, Enamoradas y Esclavos Negros). Las lavanderas, mujeres blancas, lavan sus ropas cerca del río y comentan, a modo de coro griego, la escena, relatando los acontecimientos y juzgándolos. Sin embargo, a medida que avanza la trama, se irán aproximando a la figura de Medea, rompiendo su inicial prejuicio racial e identificándose con ella. De este modo, el rechazo inicial, a medida que perciben el abandono del marido traidor, se transforma en compasión por el sufrimiento, expresada por el coro de Lavanderas a través de una sentencia universal: «Dor de branco... dor de negro, ela é sempre a mesma dor» (Olavo, 1961: 226).

\subsection{La nodriza}

Es uno de los personajes más estables en cualquiera de estas versiones. Fiel a los originales, tanto de Eurípides como de Séneca, aconseja, reprocha con cariño, mima a Medea, desde la experiencia y la autoridad que le confiere su cercana presencia. Es su confidente absoluta y, en ocasiones, la narradora de las acciones que se van a desarrollar. Todas ellas, como su referente euripideo ${ }^{18}$, apuntan la idea de que el origen de su desgracia es haberse alejado de su tierra.

La negra Ama de Olavo también representa la referencia a los antepasados. Es una anciana que debe ser respetada y que lleva el conocimiento de toda una vida. Tiene visiones cuando rasga la arena del suelo y simbólicamente representa a los ancianos del pueblo africano. Estructuralmente desarrolla la misma función de narradora de los sucesos que precedieron a la acción dramática, pero esta Ama no solo es condescendiente con Medea sino que, además de ser consciente de su miedo y del terrible futuro de exilio que les espera ${ }^{19}$, es inflexible e inmutable con el pasado que atormenta a Medea:

Ама: Traição! Medea vende os irmãos... E o moço guerreiro, a esperança da raça, apodrece na mata com o veneno de sua irmã.

MedeA: Língua de cobra, maldita! Cala-te, ou nunca mais falarás...

Ама: E partiu deixando mortos pai e irmão (Olavo, 1961: 205).

\footnotetext{
18 Medea, 34-35 (Eurípides, 1991: 214): «Nodriza: [...] La infortunada aprende, bajo su desgracia, el valor de no estar lejos de la tierra patria».

19 Olavo (1961: 226): «Ама: [...] Para onde irá vosmicê? Nâo há mais ninguém agora, nem uma terra, uma casa onde possa se abrigar».
} 
La Nodriza de Juan Ríos ${ }^{20}$ mantiene también ese perfil de consejera que apela a la condición natural e indígena de Medea en La Selva:

Nodriza: Princesa india, ¡cuídate de la intrusa rubia! ¡Cuídate de su piel! ¡Cuídate de su rostro! ¡Cuídate de su voz! (Ríos, 1961: 446).

Nodriza: Princesa deplorable, ¡no te olvides de tu sangre!... ¡Oh funesta, no renuncies a tu raza! (Ríos, 1961: 464).

La Princesa: (A la Nodriza) Voz de mi raza, antigua madre, noche remota (Ríos, 1961: 465).

La Vieja de Cureses, mezcla de Nodriza euripidea y transposición del sabio y anciano Tiresias, es una hechicera adivinadora, una Sibila del desierto que cumple dos importantes funciones en el desarrollo de la trama de $L a$ Frontera. Por un lado, es la incitadora de las crueles acciones de Bárbara:

Vieja: Hacé un conjuro...Vos sabís tuitas las cosas e la cencia y la hechicería... lo aprendiste cuando mamabas... Cortá la racha india... cortala... Las mujeres sabemos cómo atar a loj hombres... y vos, más que tuitas, tenís tus secretos (Cureses, 1964: 11).

Vieja: Disátate, india, demostrá tuito lo que podís (Cureses, 1964: 30).

VIEJA: ¡Aráñales el corazón pa que apriendan!... No te quedís ahí como estaqueada... dispirtá tuitas tus juerzas pa que apriendan a respetar los sentimientos del que sufre... No te demorés, india... e sus corazones arrancáselos como fruta podrida... io mesmita te ayudaré... hacelo, india, hacelo... tenís que poder... te robaron tuito lo tuyo... hasta el mesmito Jasón...Levantá esos ojos, descargate, india... descargate como una tormenta... No rispetes nada... Encendete, india... Tenís que poder... te robaron tuito lo tuyo (Cureses, 1964: 32-33).

Y, por otro, su consejera y confidente íntima:

Vieja: Es peligroso querer tanto a un hombre... Trae disgracia el llamar a loj muertos (Cureses, 1964: 16).

Vieja: Ten cuidado, india... con tanta felicidá en la boca podís atragantarte (Cureses, 1964: 17).

\subsection{Batista y Anambá}

Si los referentes clásicos de Eurípides y Séneca son respetados en la versión peruana de La Selva y así los hijos de Medea llevan los regalos, el peplo y la corona de oro que queman a Glauce, en las tragedias de Olavo y Cureses las ofrendas mortales las llevan nuevos personajes: Batista y Anambá.

20 Remedo indudable de la Nodriza de Séneca, siempre moderando, imperativa, la ira y la furia de Medea. Así, Medea, 174-175, 381 y 425-426 (Séneca, 1979: 299, 309 y 311): «Refrena las palabras; déjate ya de amenazas, insensata. Aplaca tus impulsos»; «Detente, reprime la ira y contén ese ímpetu»; «Reponte, señora, que la desgracia te ha perturbado, serena tus impulsos». 
Lo primero que debemos destacar es que estos dos personajes sincretizan a varios argumentos de las tragedias clásicas y, en segundo lugar, que ambos comparten semejanzas en la representación y equivalencias en el desarrollo dramático. Estos personajes, Batista y Anambá, negros e indígenas, marginales incluso dentro de su comunidad, consuman la voluntad de Medea y se convierten en la mano ejecutora de su violencia.

Batista $^{21}$, en la tragedia de Olavo, es un mulato mudo, servidor de Jasón, que transita entre los blancos y los negros. Para Da Silva Carbalho (2015: 12), la «narración» muda y corporal de Batista representa la privación de los negros del lenguaje verbal y la construcción de nuevos discursos (música, danza, rituales) como resistencia y como estrategia para preservar su identidad. Medea le pide que lleve el collar hechizado a Creúsa: «Vai, Batista, vai levar à bela noiva o presente da negra que está sozinha, não tem destino nem casa, não tem mais filhos nem amor» (Olavo, 1961: 219).

El indio Anambá, en la obra de Cureses, abarca dos referencias clásicas: por un lado evoca al personaje euripideo de Egeo $^{22}$, desarrollado también en Além do rio con el capitán Egeu. Egeu le pide a Medea, con sobornos y excesos, que la ayude, con sus pociones mágicas, a solucionar sus problemas de infertilidad, pero ella, a diferencia de la Medea clásica ${ }^{23}$, no puede hacerlo porque no quiere romper el juramento hecho a Jasón de no volver a usar remedios y pócimas:

Egeu: Dá-me filhos, Medea, como os teus. [...] Pelo filho que te peço, trocarei tudo o que tenho.

MedeA: Nunca. É a minha promessa a Jasão.

EGEU: Gostas tanto dele assim?

Medea (quase consigo mesma): Por ele traí a raça, deixei mortos pai e irmão. [...]

EGEU: Em troca do filtro que pedi, terás o meu barco que vai partir para terras mais amigas, queres? (Olavo, 1961: 209-210).

Por otro lado, la contraposición simbólica desarrollada por Eurípides de un personaje sin hijos, Egeo, con otro que trama contra ellos una venganza, Medea, la recupera plenamente Cureses con Anambá y Bárbara. Para curar

21 Olavo (1961: 215): «Mestiço, nascido dos amôres sensuais do português com a escrava favorita, tem as qualidades e os defeitos dos brancos aventureiros e dos negros sofredores».

22 El rey de Atenas, que se presenta ante Medea después de haber consultado el Santuario de Febo Apolo en Delfos para buscar soluciones a su infertilidad (cf. Eurípides, Medea, 662 ss.).

23 Medea, 716-717 (Eurípides, 1991: 239): «Acabaré con tu esterilidad y haré que puedas engendrar hijos; tales son los remedios que conozco». 
su esterilidad, Anambá debe vagar durante cuatro lunas por el desierto, matar a un cristiano, arrancarle el corazón y lavarse con él. Esta vertebración argumental la aprovecha Bárbara para convencer a Anambá de que la mujer propicia para recuperar su simiente y acabar con su esterilidad no es otra que Huinca-Aurora:

BÁrbara: Encuentra a esa mujer... causa de mi infortunio... causa de mi soledad... no dejes en sus venas ni una gota de sangre... llénate las manos... déjala correr por tu vientre, que inunde la tierra toda... y que el cielo de esta pampa se la beba (Cureses, 1964: 52).

\section{Conclusiones}

Son diversas las conclusiones que extraemos del estudio de estas tres versiones del mito de Medea. La primera es que, aunque estos dramaturgos respetan, en general, los cánones tradicionales de la Medea clásica, sus personajes y estructuras se «americanizan»y se «contaminan» con el uso de contextos populares propios de las culturas indígenas americanas. El segundo hecho reseñable es que, en medio de una producción teatral sobre la Conquista de América tan delimitada espacialmente, surja, en una misma década, los años cincuenta, y en ámbitos culturales diferentes (Perú, Brasil y Argentina) un motivo mitológico grecolatino tan marcado como la figura de Medea y que esta sea utilizada con un mismo fin: centrar un debate y una discusión sobre la identidad social, histórica, cultural y étnica de sus comunidades. Además estas Medeas son revisadas también como símbolo de la sociedad de Latinoamérica, y sus hijos, criollos, negros o indígenas, simbolizan la identidad de su desigual mestizaje. Y en este punto las tres obras vuelven a confluir: la frontera, símbolo y metáfora de esta diversidad física, cultural, étnica o social, actúa como personaje y paisaje en las tres obras. El desierto pampeano en la obra argentina, la selva amazónica en la peruana, o el río en la brasileña, representan los límites dramáticos y simbólicos por los que transitan sus personajes. Y en ese transitar, la figura de Medea redefine el antagonismo entre la primitiva «barbarie» y la «supuesta» civilización, como ya hiciera Mansilla hace más de un siglo, y en las tres obras Medea plantea una frontera inversa donde ya no se sabe quién es el bárbaro y quién el civilizado.

\section{Bibliografía}

\section{Ediciones y traducciones}

Cureses, D. (1964): La Frontera. Buenos Aires, Ediciones del Carro de Tespis.

Eurípides (1991): Medea (trad. A. Medina González). En Tragedias, vol. I. Madrid, Gredos. 
Olavo, A. (1961): Além do rio. En do Nascimento, A. (ed.): Dramas para negros e prólogo para brancos: antologia do teatro brasileiro. Rio de Janeiro, TEN.

Ríos, J. (1961): Teatro I. Lima, Talleres Gráficos de Torres Aguirre.

Séneca, L.A. (1979): Medea (trad. J. Luque Moreno). En Tragedias, vol. I. Madrid, Gredos.

\section{Estudios}

Biglieri, A.A. (2015): «The Frontiers of David Cureses' La frontera». En Bosher, K. et al. (eds.): The Oxford Handbook of Greek Drama in the Americas. Oxford, OuP, págs. 417-433.

Bosher, K. et al. (eds.) (2015): The Oxford Handbook of Greek Drama in the Americas. Oxford, oup.

Bravo de Laguna Romero, F. (1999): «El mundo clásico en el teatro argentino contemporáneo». Actas del Congreso Internacional de Literatura Iberoamericana y Tradición Clásica. Barcelona, Universitat Autònoma de Barcelona-Universitat de Valencia, págs. 89-95.

- (1999): «La pervivencia de las heroínas griegas en el teatro argentino contemporáneo: una revisión del mito de Electra». Myrtia, 14, págs. 201-218.

- (2003): «Los tangos de Orfeo of Rodríguez Muñoz». Latin American Theatre Review, 37.1, págs. 117-131.

- (2010): «De la Cólquide a la Pampa: una Medea en La Frontera de David Cureses». Arrabal, 7-8, págs. 131-138.

- (2015): «Mundo clásico y crítica social en el teatro del ecuatoriano Andino Peky Moscoso». En Maestre Maestre, J.M. et al. (eds.): Humanismo y pervivencia del mundo clásico. Homenaje al profesor Juan Gil, vol. 5. Alcañiz-Madrid, IEH-CSIC, págs. 2437-2445.

Clauss, J.J. y Johnston, S.I. (eds.) (1997): Medea. Essays on Medea in Myth, Literature, Philosophy, and Art. New Jersey, Princeton University Press.

Da Silva Carvalho, A.A. (2015): «Além do Rio - uma Medea na dramaturgia do teatro negro no Brasil». Urdimento, 24, págs. 6-27.

Delbueno, M.S. (2013): «Mujeres al margen: el conflicto que establece la ley en Medea de Eurípides y en La Frontera de David Cureses». III Jornadas del Centro Interdisciplinario de Investigaciones en Género. La Plata, Universidad de La Plata (en línea: <http://www.memoria.fahce.unlp.edu.ar/trab_eventos/ev.3439/ev.3439. pdf> [consulta: 10 de enero de 2018]).

Dolle, V. (ed.) (2014): La representación de la Conquista en el teatro latinoamericano de los siglos Xx y XXI. Hildensheim-Zürich-New York, Georgs Olms Verlag.

Gentili, B. y Perusino, F. (eds.) (2000): Medea nella letteratura e nell'arte. Venezia, Marsilio.

Harrauer, C. y Hunger, H. (2008): Diccionario de mitología griega y romana. Barcelona, Herder.

Hualde Pascual, P. (2012): "Mito y tragedia griega en la literatura iberoamericana». Cuadernos de Filología Clásica: Estudios griegos e indoeuropeos, 22, págs. 185-222. 
Lasso de la Vega, J.S. (1967): Helenismo y literatura contemporánea. Madrid, Prensa Española.

Martínez Estrada, E. (1983): Muerte y transfiguración de Martín Fierro. Ensayo de interpretación de la vida argentina. Buenos Aires, Centro Editor de América Latina.

Martins, L.M. (1991): A cena em sombras: expressões do teatro negro no Brasil e nos Estados Unidos. Tesis Doctoral. Universidade Federal de Minas Gerais.

Mansilla, L.V. (1957): Una excursión a los indios ranqueles. Caracas, Biblioteca Ayacucho.

Miranda Cancela, E. (2006): Calzar el coturno americano: mito, tragedia griega y teatro cubano. La Habana, Ediciones Alarcos.

Nogueira Coelho, M.C.M. (2005): «Medéia: metamorfoses do gênero». Letras Clássicas, 9, págs. 157-178.

Pociña, A. y López, A. (eds.) (2002): Medeas. Versiones de un mito desde Grecia hasta hoy. Granada, Universidad de Granada.

- (2007): Otras Medeas. Nuevas aportaciones al estudio literario de Medea. Granada, Universidad de Granada.

Servelli, M. (2010): «¿Literatura de frontera? Notas para una crítica». Iberoamericana, X, 39, págs. 31-52. 